\title{
AN INVESTIGATION ON THE ENVIRONMENTAL IMPACT OF A PETROLEUM REFINERY AND PROPOSED METHODS FOR DECONTAMINATION OF SOIL AND GROUNDWATER
}

\author{
Masoumeh Zargar ${ }^{1}$ \\ Mohammad Hossein Sarrafzadeh ${ }^{{ }^{*}}$ \\ Bahram Taheri ${ }^{2}$ \\ ${ }^{1}$ School of Chemical Engineering, College of Engineering, University of \\ Tehran, Iran; \\ ${ }^{2}$ The International Branch (Birmingham University Program), Amirkabir \\ University of Technology, Iran; \\ *sarrafzdh@ut.ac.ir
}

\begin{abstract}
Toxicity of crude oil for the living world and ecosystems in general is a global problem of both aquatic and terrestrial environments. Therefore, the remediation of oil contaminated soils, sediments and groundwater is a major challenge for environmental research. In the target area of this survey which is a petroleum refinery near Tehran, soil and groundwater pollution, its source, contaminated area and distribution of pollution were studied. The investigations showed that the contamination of soil which is mainly silt and clay is expanded until the surface of region groundwater and formed an oily layer with different thicknesses in the whole area. According to the result of free product analysis, the free product is a multi-type mixture of oil and its main ingredients are assumed to be gasoline, kerosene, and gas oil. In addition, pollution sources in the field are thought to be underground pipes, tanks, pipeline and so on. For decontaminating of soil and water resources there are different ways including physical, chemical and biological methods or combination of two or three types of them to reduce the extent of contamination and its dangers for the region ecosystem. The free oil existing over the groundwater table could be removed by physical ways like pump and treat method but decontamination of soil is more complex. Due to long lasting contamination of the field, the existence of accumulated indigenous microorganisms and the probable ability of them to effectively biodegrade pollutants by man-assisted interventions are expected. In this survey the feasibility assessment of bioremediation alongside other ways of treatment in the investigated area is performed.
\end{abstract}

\section{KEYWORDS}

Oil contaminated soil; decontamination; bioremediation; feasibility assessment

https://doi.org/10.15626/Eco-Tech.2010.086 


\section{INTRODUCTION}

The long-term production and use of different petroleum derivatives have caused widespread contamination of soil around the facilities handling them [1]. Oil spills caused by blowouts, leakage from tanks and dumping of waste petroleum products, for example, lead to an elevated loading of petroleum hydrocarbons in soil, which results in significant decline in the quality of soil and makes it unfit for use [8]. Numerous locations polluted with petroleum hydrocarbons are being investigated each year in the context of soil remediation projects. These projects involve different aspects, mainly dealing with risk assessment and remediation strategy and require a characterization of the soil pollution in terms of chemical composition, toxicity and physicochemical properties (volatility, water solubility, degradability). From an analytical point of view it is clear that the quality of the risk assessment and the chances for a successful soil remediation will improve with the level of characterization [11].

To control the environmental risks caused by petroleum products, various new regulations have been introduced and, at the same time, research focusing on the bioremediation of contaminated soils has been boosted [6]. Bioremediation techniques are sound alternative methods for the treatment of TPH-contaminated soil. Such techniques are economically and politically attractive and have shown promising results in the treatment of soil contaminated with organic compounds, particularly with petroleum hydrocarbons [4].

Tehran Oil Refining Company (TORC) which is our target survey area is located in the south of Tehran in the core of REY industrial area. In this region, pollution of soil and groundwater by oil was actualized in 1970's and since 1980's it began to influence the life of local residents directly. Until now in order to solve this problem, some methods like pumping out the polluted groundwater and treating that, phytoremediation and etc, have been used. However, spread of the pollution had been taking place faster than the expectations, and also, there was no effective method due to the shortage of machinery and material or similar reasons. Consequently, the groundwater pollution in the region was kept expanding every year, and this pollution was compelled the residents in the area to live with suffering from a serious health hazard, particularly in recent years. At the present time, in TORC and its vicinity, polluting oil has been extended to a vast area and exists over the groundwater table. Considering the economical loss, environmental problems, effect on human body, social disadvantages and so on, caused by the leakage of these oil products, urgent restoration of these pollution sources is demanded.

This work aimed to study the suitability of bioremediation of a highly oil contaminated site by its indigenous microorganisms.

\section{MATERIALS AND METHODS}

\subsection{Soil and groundwater sampling}

In this work, sampling from constructions like Gas Sampling Hole, Soil Sampling Hole, Monitoring well and Core boring Observation Well were executed and based on the analysis have been done on the soil and groundwater samples, the extent and type of pollution were specified. The field sampling procedure was mainly accomplished according to (Hernandez, V., et al, 1999; Smith, J., et al 1988) [9], [2].

\subsection{Soil analysis}




\subsubsection{Oil content}

In this investigation, the gathered sample from Soil Sampling Hole was used to execute the quantitative analysis of the oil content of soil. The degree of the oil contamination of the soil was calculated as a mass from Total Petroleum Hydrocarbon (TPH) contained in soil of unit mass by solvent extraction method using soxhlet abstractor, Spectrophotometer and other miscellaneous equipments. The description of the method is explained in part 2.5.4. From the analysis result, it became possible to know presumption of pollution range and the degree of pollution.

\subsubsection{VOCs gas measuring}

A complete set of VOCs gas measuring instrument was used and drilling method was implemented for VOCs gas measurement by using VOC sensor. The type of VOC sensor was VOC-201H (Made by ABLE).

\subsection{Groundwater analysis}

After sampling of groundwater, different indoor examinations like concentration of suspended solids (SS) measurement, in order to standard method of SM2540D, were done on the samples to investigate the content of water pollution.

\subsection{Underground oil thickness survey}

The purpose of the oil thickness survey was to measure inside of the well and check time fluctuation of the oil thickness to estimate extent of the pollution. Interface Meter instrument was used here which by means of a probe and make different sounds can recognize liquids and interpret the thickness of different liquids which are stand over each other.

\subsection{Bioremediation experiments procedure}

In this part of the study, a feasibility assessment of bioremediation in the target area based on laboratory experiments was done in which a combined culture that was separated from contaminated soil of the region was used to biodegrade an oil contaminated soil with average contamination percent of the site soil. To evaluate this method's applicability, a series of experiments based on design of experiments by Design Expert Software were done in which a contaminated superficial soil sample of the TORC was used for preparing the mixed bacterial culture. Afterwards, the fittingness assessment of this combined culture for biodegradation of site contaminants was done.

\subsubsection{Bacterial growth and culture conditions}

For preparing the combined culture we performed as below:

Mineral Salt (MS) media which was composed of $1.0 \mathrm{~g} / \mathrm{L} \mathrm{NaNO}_{3}, 0.5 \mathrm{~g} / \mathrm{L} \mathrm{KH}_{2} \mathrm{PO}_{4}, 0.5$ $\mathrm{g} / \mathrm{L} \quad \mathrm{K}_{2} \mathrm{HPO}_{4}, 0.1 \mathrm{~g} / \mathrm{L} \quad \mathrm{MgSO}_{4}, 0.01 \mathrm{~g} / \mathrm{L} \mathrm{CaCl}_{2}, 0.001 \mathrm{~g} / \mathrm{L} \mathrm{FeSO}_{4}$, was used for cultivation. The $\mathrm{pH}$ of media was adjusted to 7.2 using $0.1 \mathrm{~N} \mathrm{NaOH}$. Furthermore, one $\mathrm{ml}$ oil from recovery wells of the refinery as carbon source was added to the media after sterilization of that.

The bacterial culture utilized in this study was isolated using the following procedure. One gram of region contaminated soil, $100 \mathrm{ml}$ of MS medium and 1\% (v/v) oil, which acted as the sole carbon and energy source, were mixed in a $250 \mathrm{ml}$ flask. Flask was 
then incubated at $160 \mathrm{rpm}$ and $30^{\circ} \mathrm{C}$ for 24 hours. Subsequently, one $\mathrm{ml}$ of the inocula (supernatants of the above cultures) was transferred to another $250 \mathrm{ml}$ flask containing $100 \mathrm{ml}$ of MS medium supplemented with oil (1\%) and was incubated for another 24 hours under the same conditions. This procedure was repeated five times. After the final transfer, $100 \mu 1$ of the culture was spread on agar medium plates and incubated for 24 hours at $30^{\circ} \mathrm{C}$. Nutrient agar medium plates were maintained at $4^{\circ} \mathrm{C}$.

\subsubsection{Design of experiments}

Design Expert 7 was used for designing of experiments and all of the statistical analysis. The method for designing was fractional factorial $1 / 2$ with resolution of $\mathrm{V}$ and ANOVA was used to determine the significance of the regression and factors. ANOVA was also used to assess differences between appropriate measured parameters. The design table is given in table 1.

\subsubsection{Soil slurries}

$10 \mathrm{~g}$ sample of sieved $(2 \mathrm{~mm})$ contaminated soil with $3 \%$ contamination with recovery wells oil was suspended in $47.5 \mathrm{ml}$ of deionized water supplemented with nitrogen and phosphorus at a $\mathrm{C}: \mathrm{N}: \mathrm{P}$ ratio of $100: 10: 1$, which is the optimal $\mathrm{C}: \mathrm{N}: \mathrm{P}$ mole-ratio recommended for bioremediation applications, in 250-ml Erlenmeyer flasks [3]. In addition, based on design table (see Table 1), $2.5 \mathrm{ml}$ of isolated microorganisms from contaminated soil and municipal activated sludge with MLSS of 12 with the optical density adjusted to 1 at $600 \mathrm{~nm}$ by autoclaved normal saline $(0.89 \% \mathrm{NaCl})$ were added to the flasks as inoculums [7].

Table 1. Design table and experimental results

\begin{tabular}{|c|c|c|c|c|c|c|c|}
\hline \multirow[b]{2}{*}{ Experiment } & \multicolumn{5}{|c|}{ Factors } & \multicolumn{2}{|c|}{$\begin{array}{l}\text { \% TPH Reduction } \\
\text { of treatment } \\
\text { samples toward } \\
\text { Control ones }\end{array}$} \\
\hline & $\begin{array}{l}\text { Combined } \\
\text { culture } \\
\text { type }\end{array}$ & $\begin{array}{c}\text { Temperature } \\
\left({ }^{\circ} \mathrm{C}\right)\end{array}$ & $\begin{array}{l}\text { Glucose } \\
\text { (g/l) }\end{array}$ & $\begin{array}{l}\text { Surfactant } \\
(\% \mathrm{~W} / \mathrm{W})\end{array}$ & $\begin{array}{c}\text { Remaining } \\
\text { time } \\
\text { (Day) }\end{array}$ & $\begin{array}{l}\text { Actual } \\
\text { Value }\end{array}$ & $\begin{array}{l}\text { Predicted } \\
\text { Value }\end{array}$ \\
\hline 1 & MO & 25 & 0 & 0 & 24 & 1.8 & 1.69 \\
\hline 2 & Sludge & 25 & 0 & 0 & 12 & 3.6 & 3.49 \\
\hline 3 & $\mathrm{MO}$ & 30 & 0 & 0 & 12 & 4.3 & 4.41 \\
\hline 4 & Sludge & 30 & 0 & 0 & 24 & 0.1 & 0.21 \\
\hline 5 & $\mathrm{MO}$ & 25 & 1 & 0 & 12 & 24.3 & 24.19 \\
\hline 6 & Sludge & 25 & 1 & 0 & 24 & 1.4 & 1.29 \\
\hline 7 & $\mathrm{MO}$ & 30 & 1 & 0 & 24 & 4.8 & 4.9 \\
\hline 8 & Sludge & 30 & 1 & 0 & 12 & 10.7 & 10.81 \\
\hline 9 & $\mathrm{MO}$ & 25 & 0 & 0.5 & 12 & 36.8 & 36.91 \\
\hline 10 & Sludge & 25 & 0 & 0.5 & 24 & 0.45 & 0.56 \\
\hline 11 & $\mathrm{MO}$ & 30 & 0 & 0.5 & 24 & 6.2 & 6.09 \\
\hline 12 & Sludge & 30 & 0 & 0.5 & 12 & 9.8 & 9.69 \\
\hline 13 & MO & 25 & 1 & 0.5 & 24 & 3.9 & 4.01 \\
\hline 14 & Sludge & 25 & 1 & 0.5 & 12 & 2.5 & 2.61 \\
\hline 15 & $\mathrm{MO}$ & 30 & 1 & 0.5 & 12 & 13.9 & 13.79 \\
\hline 16 & Sludge & 30 & 1 & 0.5 & 24 & 4.3 & 4.19 \\
\hline
\end{tabular}


Moreover, SDS surfactant (Sodium dodecyl sulfate) and Glucose, as other factors, were imported to the flasks based on the design table (see Table 1). For each flask, one flask without inoculums was used as abiotic control. Slurries were incubated at $25^{\circ} \mathrm{C}$ and $30^{\circ} \mathrm{C}$ and $140 \mathrm{rpm}$ for 12 and 24 days based on the table 1 . The solid phase was extracted as described below. Total petroleum hydrocarbon fraction (TPH) was obtained by UV spectroscopy and based on calibration curve, biotic and abiotic degradations of TPHs were acquired.

\subsubsection{Total petroleum hydrocarbon determination}

A calibration curve was prepared for oil absorption by preparing oil solution in dichloromethane (DCM) with different concentrations and measuring the optical density by UV-Vis spectroscopy (Spectroflex6600, Germany) at 400nm. The optical densities were related to concentrations of oil in all experiments and calibration line was obtained.

TPH concentration was determined by extraction of the entire soil sample. The concentration of oil in soil was determined by solvent extraction using dichloromethane. DCM $(5 \mathrm{ml})$ was added to $0.2-2 \mathrm{~g}$ washed soil (dry) in a $5 \mathrm{ml}$ capped test tube. The test tube was shaken for $1 \mathrm{~min}$ on a Mini shaker and then centrifuged for $5 \mathrm{~min}$ at $3000 \mathrm{rpm}$, after which the crude oil/DCM extract was collected into a $25 \mathrm{ml}$ volumetric flask. This process was repeated four times; the fourth extract gave the same absorbance reading as the pure DCM. All the oil/DCM extracts were collected into the volumetric flask and made up to $25 \mathrm{ml}$ with DCM [5]. Then the oil/DCM extract was centrifuged to eliminate the soil particles in solution. Absorbance of The clear solution was measured at the wavelength of $400 \mathrm{~nm}$ at $25 \pm 1{ }^{\circ} \mathrm{C}$ with a spectrophotometer (Spectroflex6600, Germany) [10]. The concentration of oil in soil was determined from the calibration curve of oil/DCM solution at $25 \pm 1{ }^{\circ} \mathrm{C}$ and the mass of the soil. The equation and that for oil removal efficiency (ORE) calculation were shown as below equation in which $\mathrm{x}$ is the TPH content in $\mathrm{g}$ and $\mathrm{y}$ is the OD which was read at $400 \mathrm{~nm}$.

$$
\begin{aligned}
& y=6.6024 x+0.0048 \\
& R^{2}=0.9982
\end{aligned}
$$

Extraction efficiency was found to be around $76 \%$. The same procedure was applied for control experiments.

Afterwards, The percentages of biotic and abiotic depletion of TPHs (D \%) was obtained by the following equations:

$$
D_{\text {Biotic }}(\%)=\frac{T P H_{\text {Control }}-T P H_{\text {Treatment }}}{T P H_{\text {Initial }}} \times 100
$$

$$
D_{\text {Abiotic }}(\%)=\frac{T P H_{\text {Initial }}-T P H_{\text {Control }}}{T P H_{\text {Initial }}} \times 100
$$


In which TPH control was the quantity of TPH obtained in controls, TPH Treatment was the quantity of TPH obtained in each treatment and TPH Initial was the initial TPH quantity present in soil.

\section{RESULTS AND DISCUTION}

\subsection{Pollution composition}

Samples of free product were collected from different locations of the region and according to the result of analysis the free product is a multi-type mixture of oil and its main ingredients are assumed to be gasoline, kerosene, and gas oil.

\subsection{Groundwater pollution}

According to the analysis results of water samples collected from Monitoring Well and aqueduct, in whole area of this investigation period, Suspended Solid (SS) was higher than the standard range of agricultural water $(100 \mathrm{mg} / \mathrm{L})$. Also, it was found that the flow direction of groundwater inside area is generally in the southwest direction and the area of pollution is spreading from southern side of the region.

\subsubsection{Oil layer thickness on the groundwater}

In wells which were excavated in order to investigate the oil layer thickness on the groundwater surface, it was specified that this layer has different thicknesses in various parts of the region and the average thickness of that is about 4 meter on the groundwater surface.

\subsection{Soil pollution}

\subsubsection{VOCs soil gas density}

In comparison with the VOCs gas distribution in the vicinity of the TORC, it was seen that VOCs gas density in TORC was considerably high. Also, according to the measured values and their distributions, a comparatively low-density domain of VOCs gas was scattered in a wide area of survey zone.

\subsubsection{Oil content in soil}

According to the results of analysis on the soil samples and VOCs gas density measurements, there is a highly polluted area around TORC and REY industrial area including 7 companies and there is a low oil-polluted area in other regions out of this border. Also, it can be mentioned that pollution is spread in the south part of TORC, especially in a region with a high VOCs gas density of over 7,500pmm and there is a region inside TORC at the east side of that where has a high oil layer thickness.

\subsection{Proposed methods for free oil collection and site remediation}

There are easier methods for removing of oil layer than soil adsorbed oil. Free oil layer could be formed on the groundwater within a well. In the investigated area, excavated wells were used to collect the oil layer on the groundwater surface by using pumping method and for oil and water separation, a simple method of decantation was used. 
It is presumed that complete collection of all oil from inside the ground by oil collection method is difficult. Based on pumping and restoration test, the time required for recovering of oil layer after pumping is about $8 \sim 14$ days.

Considering the site conditions, especially the presence of over ground refining facilities and the necessity of keeping them in operation continuously, the final stage applicable method for the ultimate removal of polluting oil in the area is bioremediation which is the application of microbiological processes to degrade or transform contaminants to less toxic or nontoxic forms. Therefore, in order to investigate the presence of indigenous oil degrading microorganisms in the site, some experiments have been done. The results of the experiments showed that indigenous microorganisms of the region could biodegrade oil contaminants in the soil and groundwater. Thus, biostimulation is a good way for decontamination of TORC.

\subsection{Influence of factors and Analysis of variance (ANOVA)}

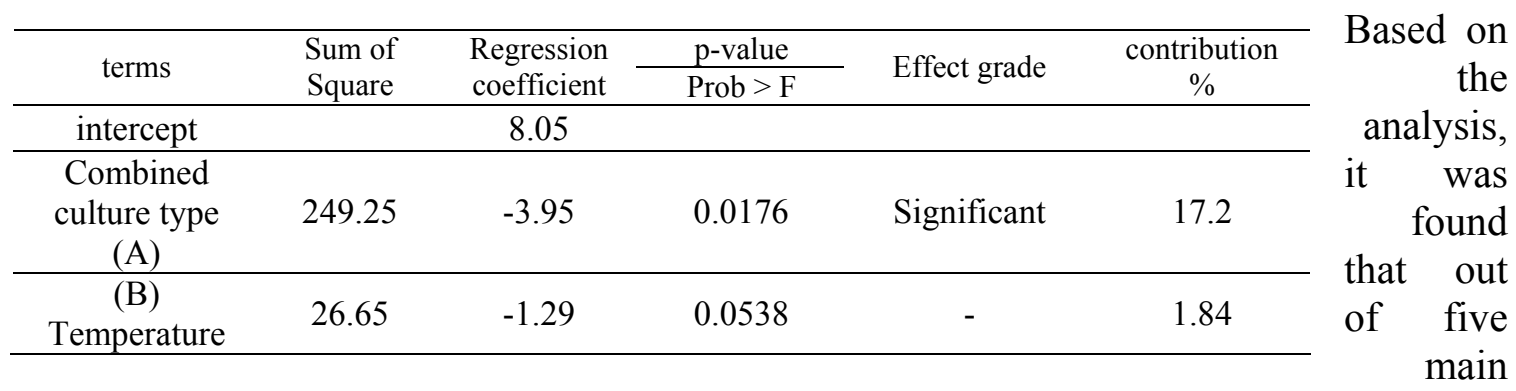

factors, three of them including surfactant, culture type and remaining time had significant effects on biodegradation of TPH with p-value $<0.05$ (see Table 2 ). The main result of these experiments was proofing the suitability of indigenous microorganisms, as was predicted, to biodegrade oil contamination of the area. Therefore, bioremediation with indigenous microorganisms alongside engineered assistances is a suitable method which can be used for decontamination of the investigated area.

Table 2. Analysis of variance (ANOVA)

\begin{tabular}{cccccc}
\hline Glucose (C) & 0.47 & 0.17 & 0.3608 & - & 0.03 \\
\hline Surfactant(D) & 45.06 & 1.68 & 0.0414 & Significant & 3.11 \\
\hline $\begin{array}{c}\text { Remaining (E) } \\
\text { time }\end{array}$ & 430.04 & -5.18 & 0.0134 & Significant & 29.68 \\
\hline AB & 185.98 & 3.41 & 0.0204 & Significant & 12.83 \\
\hline AC & 3.19 & 0.45 & 0.1528 & - & 0.22 \\
\hline $\mathrm{AD}$ & 37.06 & -1.52 & 0.0457 & Significant & 2.56 \\
\hline $\mathrm{AE}$ & 111.57 & 2.64 & 0.0264 & Significant & 7.69 \\
\hline $\mathrm{BC}$ & 35.56 & 1.49 & 0.0466 & Significant & 2.45 \\
\hline $\mathrm{BE}$ & 82.58 & 2.27 & 0.0306 & Significant & 5.69 \\
\hline $\mathrm{CD}$ & 225.37 & -3.75 & 0.0185 & Significant & 15.55 \\
\hline $\mathrm{CE}$ & 5.01 & 0.56 & 0.1229 & - & 0.34 \\
\hline $\mathrm{DE}$ & 11.14 & -0.83 & 0.083 & - & 0.77 \\
\hline
\end{tabular}




\section{CONCLUSIONS}

This work was another demonstration of the importance of water and soil decontamination in the industrial zone.

As contamination of soil and groundwater resources in industrial regions usually are simultaneous occurrences and by knowing this fact that only one method couldn't be enough for the remediation aim, treatment processes for both aquatic and terrestrial environments in polluted areas are better to be done concurrently. Moreover, combination of different remediation ways including physical, chemical and biological methods should be chosen to prevent expansion of contamination and perform decontamination process successfully.

Between different ways for decontamination of the industrial fields, bioremediation techniques are sound alternative methods for the treatment of TPH-contaminated soils. Such techniques are economically, politically and ecologically attractive and have shown promising results in the treatment of soil contaminated with organic compounds, particularly with petroleum hydrocarbons.

In the investigated area for the ultimate removal of polluting oil, considering the site conditions, especially the presence of over ground refining facilities and the necessity of keeping them in operation continuously, bioremediation as an applicable method after stopping the spillage and alongside physically collecting of oils by wells is proposed. The present investigation also revealed that the application of Design of Experiments (DOE) using fractional factorial facilitated understanding of the role of factors involved in the bio slurry process operation for treating the oil contaminated soil of the region and displayed the suitability of indigenous microorganisms for decontaminating of site.

However, new studies should be developed to optimize the rate of biodegradation and extrapolate the results from laboratory to field scale bioremediation directly.

\section{ACKNOWLEDGMENTS}

The authors would like to acknowledge the supports of the Tehran Oil Refining Company (TORC).

\section{REFRENCES}

[1] Barbee, G.C., Brown, K.W. and Donnelly, K.C. 1992, Fate of mutagenic chemicals in soil amended with petroleum and wood preserving sludges, Waste Manag. Res. 10, 73-85.

[2] Bhupathiraju, V., Hernandez, M., Krauter, P., Alvarez-Cohen, L., 1999, A new direct microscopy based method for evaluation in-situ bioremediation, Hazardous Materials B67, 299-312.

[3] Cookson, J., 1995. Bioremediation Engineering: Design and Application. McGraw-Hill, New York.

[4] Garcia-Blanco, S., Venosa, A.D., Suidan, M.T., Lee, K., Cobanli, S., Haines, J.R., 2007. Biostimulation for the treatment of an oil contaminated coastal SALT march. Biodegradation 18, 1-15.

[5] Han, M., Guodong, J., Jinren, N., 2009. Washing of field weathered crude oil contaminated soil with an environmentally compatible surfactant, alkyl polydlucoside. Chemosphere 76, 579-586. 
[6] Margesin, R., Schinner, F., 2001a. Biodegradation and bioremediation of hydrocarbons in extreme environments, Applied Microbiology and Biotechnology 56, 650-663.

[7] Partovinia, A., 2010, Carbon content reduction in a model reluctant clayey soil: Slurry phase n-hexadecane bioremediation, Hazardous Materials

[8] Shabir, G., Afzal, M., Anwar, F., Tahseen, R., Khalid, Z. M., 2008. Biodegradation of kerosene in soil by a mixed bacterial culture under different nutrient conditions, Biodegradation 61, 161-166.

[9] Smith, J., Steele, D., Malley, M., and Bryant, M., 1988. Groundwater Sampling, In: Principles of Environmental Sampling, L.H. Keith (ed.), ACS Professional Reference Book, American Chemical Society, Washington, DC, 255-260.

[10] US EPA, 2000, National Oil and Hazardous Substances Pollution Contingency Plan, 40 CFR Part 300, App. C, 7-1-03 Edition, 224-228.

[11] Van De Weghe, H., Vanermen, G., Gemoest, J., Lookman, R., Bertel, D., 2006. Application of comprehensive two dimentional gas chromatography for the assessment of oil contaminated soils, Chromatography A1137, 91-100. 